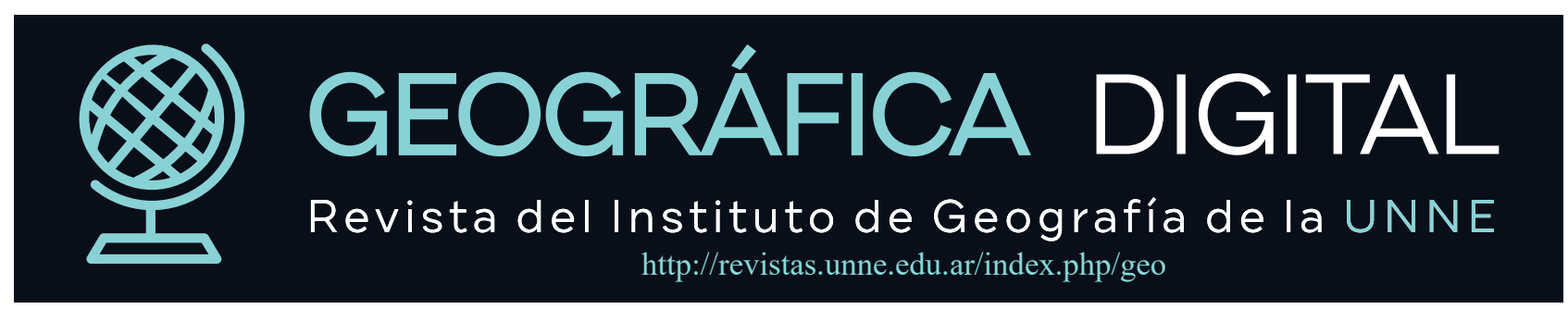

Revista Geográfica Digital, 2021, Vol. 18, No36, 20-36 pp., E-ISSN: 1668-5180: DOI: http://dx.doi.org/10.30972/geo.18364592

\title{
Mapa de Riesgo a Inundaciones para el sector norte del Ejido Urbano de la ciudad de Mar del Plata
}

\section{Flood Risk Map for the Mar del Plata city's north sector}

\author{
Montenegro, M. ${ }^{\text {, Burla, J. M. }}$, Socrate, J. ${ }^{3}$, Suarez, A. ${ }^{4}$ \\ 1'Área Gis - Gerencia de Sistemas, Obras Sanitarias SE Mar del Plata - Batán. montenegro.marisa@osmgp.gov.ar \\ 2Área Gis - Gerencia de Sistemas, Obras Sanitarias SE Mar del Plata - Batán. burlajuan@gmail.com \\ ${ }^{3}$ Área Gis - Gerencia de Sistemas, Obras Sanitarias SE Mar del Plata - Batán. julisocrate@gmail.com \\ ${ }^{4}$ Subgerencia Desarrollo del Planeamiento - Gerencia de Planeamiento y Obras, Obras Sanitarias SE Mar del Plata - Batán. suarezam10@gmail.com
}

\section{R E S U M E N}

Palabras clave:

mapa de riesgo

mapa de vulnerabilidad

mapa de amenaza

SIG

objetivos de desarrollo sostenible
Los Mapas de Riesgo son representaciones cartográficas que permiten visualizar la distribución de determinados riesgos en un territorio específico, en este caso, anegamientos producidos por precipitaciones recurrentes. En el presente trabajo se dispone a realizar un Mapa de Riesgo de Inundaciones (MRI) para un sector del norte de la ciudad de Mar del Plata. Varios proyectos de agua y saneamiento para la ciudad de Mar del Plata son desarrollados por Obras Sanitarias Sociedad de Estado (OSSE). Este MRI se acopla al Sistema de Información Geográfica (SIG) de la empresa y servirá para gestionar y planificar futuros proyectos. Este trabajo muestra la primera etapa del proyecto del MRI, el cual tiene como objetivo cartografiar toda la ciudad y ubicar sectores con alto riesgo para poder prevenir potenciales conflictos con la infraestructura de la empresa y posibles consecuencias sobre la población local. También se tuvieron en cuenta los Objetivos de Desarrollo Sostenible de la agenda 2030. Mediante el uso del software libre QGIS se realizó un análisis multivariable, siguiendo los lineamientos legales y de recomendación de organismos locales, nacionales e internacionales. Se obtuvo como resultado un MRI para cuatro sectores del norte de la ciudad, ubicando distintas zonas de riesgo: fueron analizadas y corroboradas in situ y con fotografías históricas georeferenciadas de diversas inundaciones. Dentro de las conclusiones se determinan los próximos pasos a seguir para lograr un MRI de todo el ejido urbano de Mar del Plata y cómo ampliar el proyecto a los sectores periurbanos del partido de General Pueyrredon.

\section{A B S T R A C T}

A Risk Map is a cartographic representation that allows visualizing the distribution of certain disaster risks in a specific territory, in this case, flood caused by recurrent rainfall. In the present paper a Flood Risk Map was made for the Mar del Plata city's north sector. Several water and sanitation projects are being developed for Mar del Plata by Obras Sanitarias Sociedad de Estado (OSSE). This Flood Risk Map is coupled with the company's Geographic Information System to provide detailed risk data for the city's different sectors. This will be used to manage and plan future projects. This paper shows the Flood Risk Map project's first stage, which aims to map the entire city and locate high-risk sectors in order to prevent potential conflicts with the company's infrastructure and possible consequences on the local population. The Sustainable Development Goals of the 2030 Agenda were also taken into account. Using the open source software QGIS, a multivariate analysis was carried out, following local, national and international organizations legal guidelines and recommendations. A Flood Risk Map was obtained for four sectors of the city's north region, locating different risk areas which were analyzed and corroborated on site and with georeferenced historical photographs of various floods. Among the conclusions there are determined the next steps to be taken to achieve a Flood Risk Map of the entire Mar del Plata's urban-grid and how to expand the project to the peri-urban sectors of the General Pueyrredon Partido. 


\section{Introducción}

Los Mapas de Riesgo son representaciones cartográficas que permiten visualizar la distribución de determinados riesgos de desastre en un territorio específico, en este caso, anegamientos producidos por precipitaciones recurrentes. Estos son el resultado de la combinación de mapas de amenaza y mapas de vulnerabilidad, los cuales surgen a partir de un conjunto de variables y sus correspondientes indicadores específicos. Estas representaciones se utilizan como herramienta de análisis esencial que permiten identificar zonas de mayor o menor riesgo frente a diferentes peligros (Renda et al., 2017).

En los últimos años el cambio climático se ha convertido en uno de los temas más preocupantes a nivel mundial, tanto en las agendas políticas como en las académicas. Han surgido distintos informes evaluando las posibles consecuencias que este fenómeno podría llegar a tener en las diferentes regiones y lugares del mundo. (Grupo Intergubernamental de Expertos sobre el Cambio Climático [IPCC], 201919; IPCC, 2019²; IPCC, 2018). Si bien a nivel regional latinoamericano existen diversos estudios (Armenta Parras et al., 2015; Banco Interamericano de Desarrollo [BID], 2014; Ministerio de Medio Ambiente del Gobierno de Chile, 2014; Marengo, 2002), a nivel país, los reportes e informes sobre Cambio Climático están surgiendo poco a poco, sobre todo a partir de la generación de la Ley sobre Presupuestos Mínimos de Adaptación y Mitigación al Cambio Climático Global (Ley N²7.520). A partir de allí, el sector académico ha comenzado a elaborar tanto diagnósticos sobre los efectos del cambio climático (Renda et al., 2017; Secretaría de Ambiente y Desarrollo Sustentable [SAyDS], 2015), como de medidas de adaptación y mitigación sobre el mismo (Uijt den Bogaard \& Cotelo, 2020; Ciaffardini et al., 2018; Gobierno de la ciudad de Santa Fe, 2014). A nivel internacional, si bien existen análisis que elaboran metodologías y resultados con respecto a las inundaciones en ciudades del mundo, estos suelen tratar sobre aquellas que son interceptadas por cursos de agua a cielo abierto (Jha, Bloch \& Lamond, 2012; Tucci, 2007). Sin embargo, también se han desarrollado trabajos que hablan específicamente sobre inundaciones en aglomerados urbanos por precipitaciones (Quesada-Román et al., 2021; García-Soriano et al., 2020; Olcina Cantos, 2017; Sánchez Gonzáles 2011; Hernández \& Vieyra, 2010).

Con respecto a los MRI, en Argentina existen ya algunos estudios realizados (Etulain, 2017; Meza et al., 2017; Schomwandt et al., 2016). Específicamente en la ciudad de Mar del Plata, si bien se han hecho estudios sobre la vulnerabilidad social frente a eventos de desastres (Daga, 2014), no existen todavía proyectos que traten sobre evaluación del riesgo por inundaciones en eventos de lluvias recurrentes. Por ello es que el trabajo aquí presentado es de gran relevancia para el aglomerado marplatense. Además, la reciente afiliación de la ciudad a la Red Argentina de Municipios para el Cambio Climático (RAMCC) también motiva a la continuación de estos estudios.

Dada la variabilidad espacio-temporal de la amenaza y factores de vulnerabilidad, la actualización de la cartografía es fundamental, sobre todo para lograr que su aplicación sea efectiva. Por ello, el uso de herramientas como los Sistemas de Información Geográfica (SIG) son eficaces, dada su versatilidad para administrar información a medida que se vaya modificando, generando y actualizando.

Debido a lo anteriormente mencionado, es que se plantean los siguientes objetivos del trabajo:

- Desarrollar un Mapa de Riesgo a Inundaciones para el área urbana del sector norte de la ciudad de Mar del Plata.

- Determinar sectores de riesgo dentro del área de estudio para planificar obras de mitigación y contención frente a escenarios de lluvias recurrentes.

- Integrar el mapa de riesgo resultante al sistema de información geográfica OSSE, Mar del Plata.

- Contribuir a definir indicadores para algunas de las metas de los Objetivos de Desarrollo Sostenible (ODS) referidos a la gestión de riesgos en relación con el Agua y el Saneamiento y Acción por el Clima de la Agenda 2030.

En las siguientes secciones se desarrollará tanto el marco teórico, como los materiales y métodos utilizados, para luego presentar los principales resultados obtenidos dentro del área de estudio. En las conclusiones del trabajo, se enuncian las consecuencias primordiales de los eventos analizados y se sugieren nuevos posibles caminos por los que continuar trabajando.

\section{Marco teórico}

El análisis del riesgo se refiere a la estimación de daños, pérdidas y consecuencias que pueden ocasionarse a raíz de uno o varios escenarios de desastre, y trata de determinar la probabilidad de ocurrencia y la magnitud de los daños por fenómenos naturales extremos (Kohler, Jülich \& Bloemertz 2004). 
Para la elaboración del mapa en cuestión, es necesario generar un análisis de las variables que lo componen: la amenaza, entendida como el factor externo y posibilidad que ocurra un fenómeno o un evento adverso, en un momento, lugar específico, con una magnitud determinada y que podría ocasionar daños a las personas, a la propiedad (Ley 27.287, 2016); y la vulnerabilidad de la población. Ésta es entendida por la Ley antes mencionada como un factor interno de una comunidad o sistema, que la hacen susceptibles de sufrir un daño o pérdida grave en caso de que se concrete el fenómeno adverso.

Este trabajo se enmarca dentro de la Ley 27.287 del año 2016, denominada "Sistema Nacional para la Gestión Integral del Riesgo y la Protección Civil”, la cual tiene como objetivo crear un sistema que integre las acciones y articule el funcionamiento de organismos (a nivel Nacional, Provincial, Municipal, ONG y la sociedad civil) para fortalecer y optimizar las acciones destinadas a la reducción de riesgos, el manejo de la crisis y la recuperación de la misma. Busca la protección integral de las personas, las comunidades y el ambiente. El Sistema Nacional para la Gestión Integrada del Riesgo y la Protección Civil está conformado por una serie de instituciones consultivas, como el Consejo Federal de Gestión Integral del Riesgo y la Protección Civil y el Consejo Nacional para la Gestión Integral del Riesgo y la Protección Civil.

Por otro lado, la motivación del mismo nace como oportunidad para que OSSE colabore con los Planes Locales de Acción Climática, en el contexto de la Red Argentina de Municipios para el Cambio Climático. Esta surge con la necesidad de crear "una herramienta de planificación estratégica de un gobierno local que permita optimizar la gestión de recursos técnicos y económicos, internos y externos, para hacer posible la transición hacia una ciudad resiliente" (Red Argentina de Municipios frente al Cambio Climático [RAMCC], 2020, p.1). Además, esta promueve la adhesión a la Agenda 2030 de los Objetivos de Desarrollo Sostenible (ODS), que fuera aprobada en 2015 por la Asamblea General de las Naciones Unidas, y plantea una visión renovada ante la sostenibilidad económica, social y ambiental, además de funcionar como un marco de referencia para el trabajo de las instituciones involucradas (Naciones Unidas, 2018).

El presente trabajo se identifica con algunos de estos retos para la gestión de riesgos en relación con el ODS 6 ‘Agua y el Saneamiento' y ODS 13 'Acción por el Clima' ya que afronta las siguientes temáticas que aportarían a definir indicadores que los puedan evaluar:

- Mejorar el conocimiento acerca de los barrios en situación de riesgo de desastres relacionados con el agua, especialmente aquéllos que puedan originarse por el cambio climático.

- Adoptar una gestión integrada del riesgo de desastres, incluyendo enfoques estructurales y no estructurales, para reducir la mortalidad y las pérdidas económicas causadas por desastres relacionados con el agua.

- Implementar sistemas de alerta temprana centrados en las personas para las comunidades de mayor riesgo expuestas a desastres relacionados con el agua.

- Aplicar un enfoque de preparación de principio a fin para la gestión de desastres relacionados con el agua con el fin de ver si las necesidades de las comunidades de usuarios se están satisfaciendo.

Por último, el trabajo también se contextualiza en la Ley 27.520 denominada de "Presupuestos Mínimos de Adaptación y Mitigación al Cambio Climático Global”. Fue publicada en el Boletín Oficial de la República Argentina el 20 de diciembre de 2019. Sus tres objetivos principales son

establecer estrategias, medidas, políticas e instrumentos relativos al estudio de
impacto, la vulnerabilidad y las actividades de adaptación al Cambio Climático que
puedan garantizar el desarrollo humano y de los ecosistemas; asistir y promover el
desarrollo de estrategias de mitigación y reducción de gases de efecto invernadero
en el país; y reducir la vulnerabilidad humana y de los sistemas naturales ante el
Cambio Climático, protegerlos de sus efectos adversos y aprovechar sus beneficios. (Ley 27.520, 2019, p.1)

Para el caso del mapa de Vulnerabilidad, las variables seleccionadas responden a tres cuestiones fundamentales, y sobre las cuales estas se consignaron:

- Exposición y susceptibilidad física de la población, es decir, el potencial daño que la sociedad podría llegar a sufrir frente al fenómeno natural.

- Fragilidad socioeconómica.

- La falta de resiliencia, o recuperación ante el fenómeno o desastre natural.

Para el caso del Mapa de Amenaza, y siguiendo las recomendaciones de Renda et al. (2017), las variables tienen en cuenta una serie de elementos: 
- La zona de origen de la amenaza.

- La zona afectada, o que es tendiente a serlo debido a sus características físico-naturales.

- La causa o causas que generan el evento de desastres. trabajo.

A continuación se desarrollarán los materiales y métodos propuestos para la generación de este

\section{Materiales y métodos}

\subsection{Delimitación espacial y temporal}

El proyecto del Mapa de Riesgo para la ciudad de Mar del Plata de Obras Sanitarias Sociedad de Estado (OSSE) del municipio de General Pueyrredón, se sustenta sobre trece grandes sectores urbanos del Partido de General Pueyrredón, Provincia de Buenos Aires, Argentina (Figura 1 y 2). En esta primera etapa del proyecto, se considera un área importante conformada por cuatro sectores, los cuales se denominaron: Marcos Sastre, Alió, Constitución y Los Pinares, debido a las avenidas principales que recorren el sector en los primeros tres casos, y por el nombre del barrio con más superficie en el sector en el último caso. Estos cuatro sectores se ubican en la parte norte del ejido urbano de la ciudad de Mar del Plata y son coincidentes con los límites de varios radios censales seleccionados. Su elección se debe principalmente al conocimiento previo de los integrantes del grupo, habiendo ya trabajado en este sector en proyectos anteriores, lo cual facilitó la recopilación de información.

En las etapas siguientes, se continuará con los restantes sectores y se comenzará a trabajar con las variables adaptadas al área rural, dadas las diferencias de comportamiento que presentan ambas zonas, principalmente en los escurrimientos superficiales.

Figura 1. Ubicación del área de estudio.

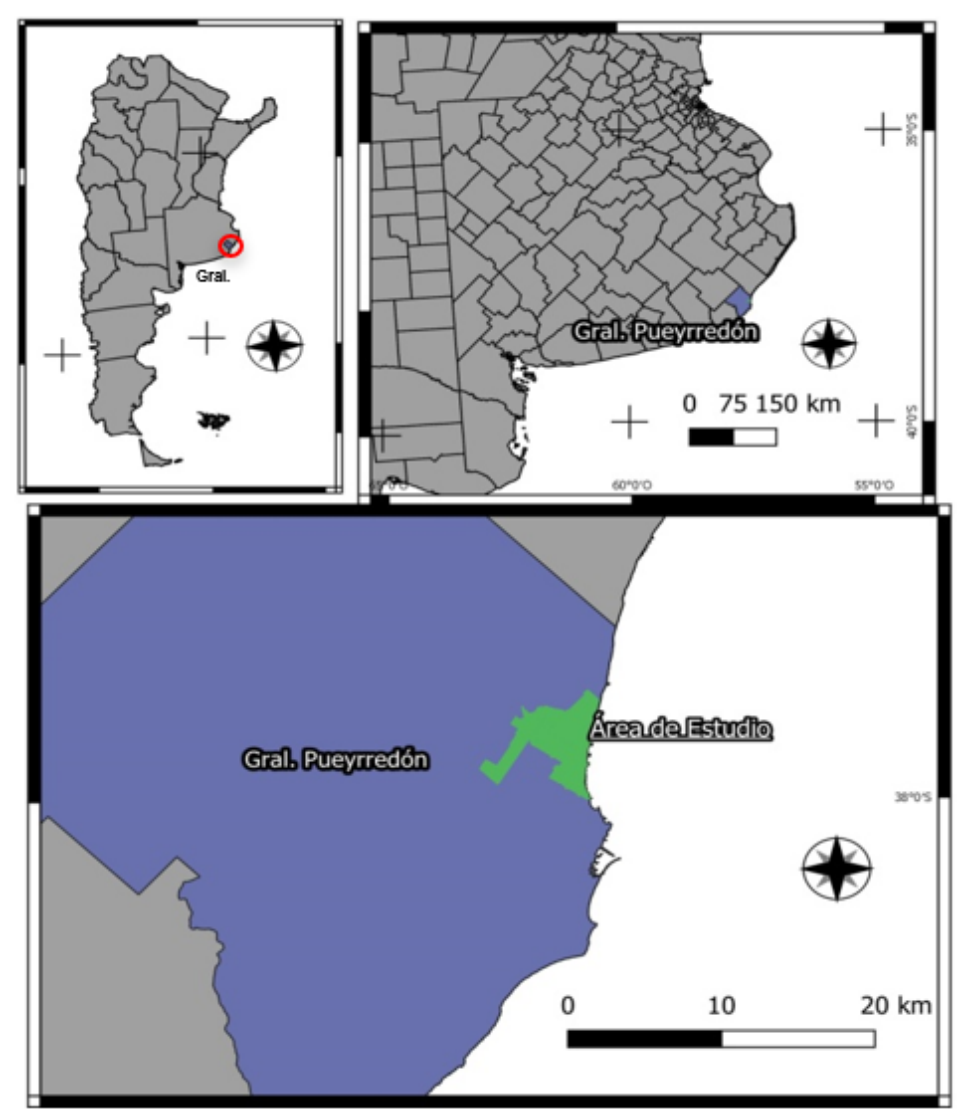

Fuente: elaboración propia. 
Figura 2. Sectorización de la Ciudad de Mar del Plata. Los cuatro sectores elegidos se encuentran delimitados con línea de color rojo.

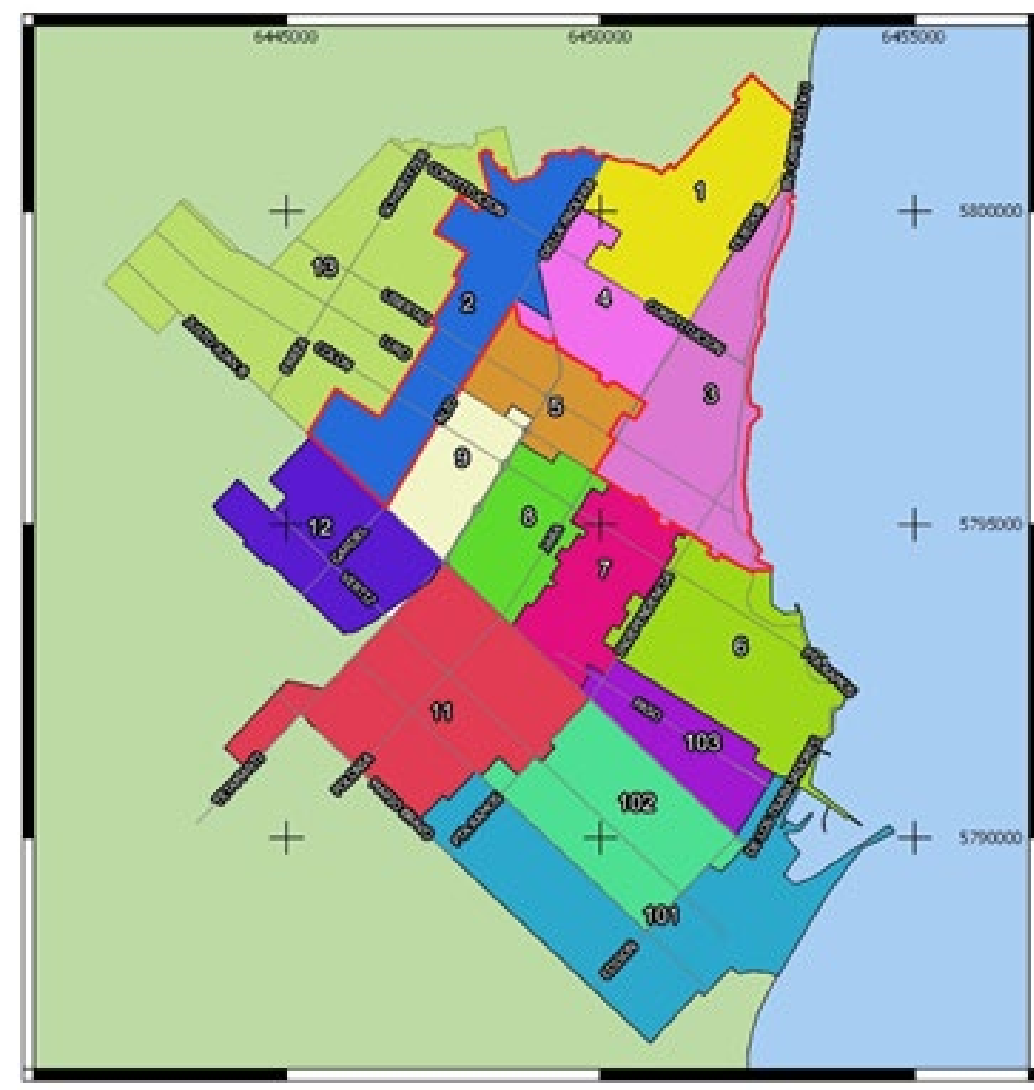

Sectores de Estudio de la. ciudad de Mar del Plata

Fuente: elaboración propia.

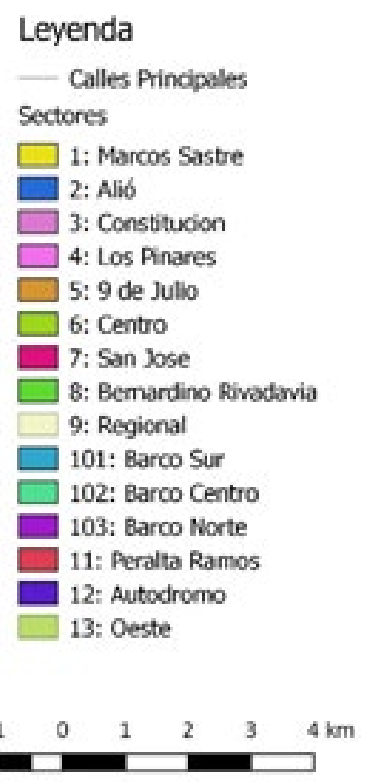

\subsection{Técnicas de análisis}

El Mapa de Riesgo se realiza a partir de un análisis multivariable que conforman a los Mapas de Vulnerabilidad y de Amenaza. Se utilizan los software QGIS 2.14 para el análisis de la información y la producción de los mapas, e IDRISI Selva para la generación de los mapas NDVI.

Las variables se seleccionan a partir de las recomendaciones de Renda et al. (2017) y de los datos disponibles. A cada una de ellas se les otorga una categoría de 1(uno) a 4(cuatro), en donde se delimita el nivel de amenaza o vulnerabilidad que presenta el área de estudio. Además, a cada una se le aplica una ponderación, es decir, un valor X, el cual se encuentra relacionado con la importancia que posee la variable en el Mapa de Riesgo. La técnica de la ponderación es muy importante dado que permite diferenciar a las variables entre sí y valorar más aquellas que tienen mayor influencia en el Mapa de Riesgo por inundación. Para calcularla se multiplica el valor de la variable (1 a 4) por la ponderación correspondiente.

Para el análisis de este mapa, cada sector se divide siguiendo los radios censales utilizados para el Censo Nacional de Población y Vivienda de 2010. Las variables seleccionadas para este estudio son las siguientes:

- Asentamientos precarios.

- Áreas verdes.

- Disponibilidad del servicio de agua.

- Disponibilidad del servicio de cloacas.

- Densidad de población.

- Densidad de viviendas.

- Calidad constructiva de la vivienda.

- Pobreza. 
A continuación, se consigna la forma en que son calculadas cada una de ellas.

Asentamientos precarios: junto con la pobreza, es considerada una de las más importantes dentro de este mapa, ya que representan a la población más vulnerable frente a eventos de inundación. La información se obtiene a partir de la combinación de varias bases de datos: Municipalidad del Partido de Gral. Pueyrredón, OSSE y el relevamiento realizado por la ONG Mar del Plata Entre Todos. Para esta variable, simplemente se considera la presencia o ausencia de los asentamientos dentro de cada radio.

Disponibilidad de Servicio de Agua: esta variable es incluida en el Mapa de Riesgo debido a las recomendaciones de distintos manuales (Renda et al., 2017; Ciaffardini et al., 2018; Tucci, 2007) de anexar variables relacionadas a los servicios, que denota la relevancia de tener agua potable de red frente a un evento de estas características. Se obtiene un promedio de la cantidad de manzanas con servicio por radio. Para ello, se calcula desde el software la cantidad de manzanas con servicio en el sector y se lo divide por la cantidad de manzanas total que este posee.

Disponibilidad de Servicio de Cloaca: al igual que en la anterior, se calcula el porcentaje de manzanas con servicio de cloaca respecto a la cantidad total. Si bien su relevancia es similar a la del agua, se le adjudica una ponderación un poco más alta, dado que, en los eventos de precipitaciones recurrentes, una parte importante del agua de lluvia se filtra en los conductos de manera natural o por acción antrópica, colaborando de manera colateral con el escurrimiento de las aguas por precipitación. Si bien no es correcto el comportamiento y no siempre sucede, se contempla la posibilidad.

Densidad de población: el objetivo de esta variable es calcular la cantidad de población por radio que se podría ver afectada en el caso que se produzca un fenómeno de inundación. Para deducir esta variable primero se contabiliza la población total por cada radio, a partir de los resultados del Censo 2010. A ese valor se lo divide por la superficie del radio y allí se obtiene la densidad poblacional del mismo. Una vez hecho esto, se calculan cuatro intervalos iguales entre el valor máximo y mínimo del sector. Así, el corte que presenta la mayor cantidad de población con respecto a su área será Vulnerabilidad 4 (Vulnerabilidad Muy Alta), el que sigue Vulnerabilidad 3, Vulnerabilidad 2. El intervalo que representa la densidad poblacional más baja será considerado como Vulnerabilidad 1 (Vulnerabilidad Baja).

Densidad de vivienda: al igual que la variable anterior, esta se calcula considerando la cantidad de viviendas en el radio dividido el área del mismo. Este dato se extrae de las planillas del Censo de 2010, considerando a la vivienda como toda construcción que hay en el radio, desde casas habitadas hasta comercios. A partir de la relación que se calcula, se toma el valor máximo y mínimo y se divide en cuatro intervalos. De estos, el que presenta el valor de densidad más alto será Vulnerabilidad 4 (Vulnerabilidad Muy Alta), luego Vulnerabilidad 3, Vulnerabilidad 2. Vulnerabilidad 1 (Vulnerabilidad Muy Baja) responde a la menor densidad de vivienda del sector.

Calidad constructiva de la vivienda: se busca caracterizar la calidad de la construcción de las viviendas del radio (Instituto Nacional de Estadísticas y Censos [INDEC], 2020). Se toman las categorías propuestas por el Censo para generar los valores de vulnerabilidad: satisfactoria, básica e insuficiente. La primera engloba las viviendas que disponen de materiales resistentes, sólidos y con la aislación adecuada. A su vez, también disponen de cañerías dentro de la vivienda y de inodoro con descarga de agua. Representa la vulnerabilidad más baja. La calidad constructiva de la vivienda básica refiere a aquellas que no cuentan con elementos adecuados de aislación o tienen techo de chapa o fibrocemento. Al igual que la calidad satisfactoria, cuentan con cañerías dentro de la vivienda y de inodoro con descarga de agua. Representa la vulnerabilidad intermedia. Por último, la calidad constructiva de vivienda insuficiente engloba las viviendas que no entran en los dos grupos anteriores y designa la vulnerabilidad más alta.

Pobreza: se tiene en cuenta el nivel educativo del Jefe de Hogar de cada radio, y se lo combina con el indicador "Relación de Dependencia". Este último refiere a la cantidad de niños entre 0-14 que dependen de la población de entre 15-64 en el radio. Ambas son extraídas de la base de datos del Censo 2010. En primer término se otorga un valor de vulnerabilidad a cada una de las dos variables. Luego, se suman los valores de ambas vulnerabilidades para generar la Vulnerabilidad subtotal, y así lograr la Vulnerabilidad Total. Esto se realiza para generar una relación entre ambas variables sin realizar operaciones matemáticas entre ellas, y no distorsionar los resultados. Los valores obtenidos muestran que cuando el porcentaje de Relación de dependencia supera el $45 \%$ (es decir que hay una cantidad elevada de población infantil en relación a la población adulta), se considera una Vulnerabilidad Muy Alta. Cuando este porcentaje es menor al 29\%, se considera una Vulnerabilidad Baja, porque hay menos población de riesgo. Para la variable Nivel Educativo del jefe de hogar se tuvo el mismo criterio. Generalmente, cuando este es más alto, suele significar que hay mayores ingresos, y por lo tanto el nivel de vulnerabilidad es más bajo. Se calculó en porcentajes la cantidad de Jefes por Radios que no tenían el nivel inicial, primario, Escuela Primaria Básica o Especial completo. Entonces, a mayor porcentaje, menor nivel educativo del radio y, por 
tanto, mayor vulnerabilidad. Una vez obtenidos estos números, se sumaron y se les otorgaron los valores de Vulnerabilidad total.

Áreas Verdes: se considera la presencia o ausencia de los mismos dentro de los radios. Reconociendo que estos espacios (plazas y parques) funcionan como superficies filtrantes al momento de la precipitación, se considera positiva su presencia. Como no hay este tipo de espacios en todos los radios, no se le dio una ponderación extrema. Para su cartografía, se extrajo información procedente de la base de datos OpenStreetMap de la categorías leisure: park. Esto se procesó mediante el plugin QuickOSM disponible en el software QGIS 2.14 utilizado.

En la Tabla 1, se detallan las variables hasta aquí descritas, los grados de vulnerabilidad que cada una posee (con su correspondiente significado) y el nivel de ponderación que se le otorga a la misma.

Tabla 1. Variables de Vulnerabilidad.

\begin{tabular}{|c|c|c|c|}
\hline Variable & Descripción & Ponderación & Grado de Vulnerabilidad \\
\hline $\begin{array}{l}\text { Asentamientos } \\
\text { precarios. }\end{array}$ & $\begin{array}{l}\text { Representa a la población más } \\
\text { vulnerable frente a eventos de } \\
\text { inundación. Se calcula a partir de la } \\
\text { presencia o ausencia de los mismos } \\
\text { en el radio bajo estudio. }\end{array}$ & 10 & $\begin{array}{l}\text { Vulnerabilidad 4: presencia de } \\
\text { asentamientos en el radio. } \\
\text { Vulnerabilidad } 1: \text { ausencia de } \\
\text { asentamientos en el radio. }\end{array}$ \\
\hline $\begin{array}{l}\text { Disponibilidad } \\
\text { de servicio: } \\
\text { Agua. }\end{array}$ & $\begin{array}{l}\text { Se calcula a partir del porcentaje de } \\
\text { cobertura de radio que cuenta con } \\
\text { servicio de agua, proporcionado } \\
\text { por OSSE. }\end{array}$ & 1 & $\begin{array}{l}\text { Vulnerabilidad 4: menos del } 25 \% \text { del } \\
\text { radio con cobertura de servicio. } \\
\text { Vulnerabilidad 3: entre un } 25-50 \% \\
\text { del radio con cobertura de servicio. } \\
\text { Vulnerabilidad 2: entre un } 50-75 \% \\
\text { del radio con cobertura de servicio. } \\
\text { Vulnerabilidad 1: más del } 75 \% \text { del } \\
\text { radio con cobertura de servicio. }\end{array}$ \\
\hline $\begin{array}{l}\text { Disponibilidad } \\
\text { de servicio: } \\
\text { Cloaca. }\end{array}$ & $\begin{array}{l}\text { Se calcula a partir del porcentaje de } \\
\text { cobertura de radio que cuenta con } \\
\text { servicio de cloaca, proporcionado } \\
\text { por OSSE. }\end{array}$ & 2 & $\begin{array}{l}\text { Vulnerabilidad 4: menos del } 25 \% \text { del } \\
\text { radio con cobertura de servicio. } \\
\text { Vulnerabilidad 3: entre un } 25-50 \% \\
\text { del radio con cobertura de servicio. } \\
\text { Vulnerabilidad 2: entre un } 50-75 \% \\
\text { del radio con cobertura de servicio. } \\
\text { Vulnerabilidad 1: más del } 75 \% \text { del } \\
\text { radio con cobertura de servicio. }\end{array}$ \\
\hline $\begin{array}{l}\text { Densidad de } \\
\text { población }\end{array}$ & $\begin{array}{l}\text { Se calcula considerando la cantidad } \\
\text { de habitantes en el radio dividido el } \\
\text { área del mismo. }\end{array}$ & 6 & $\begin{array}{l}\text { Se calculan cuatro intervalos iguales } \\
\text { entre el valor máximo y mínimo del } \\
\text { sector. Así, el corte que presenta la } \\
\text { mayor cantidad de población con } \\
\text { respecto a suárea será Vulnerabilidad } \\
4 \text { y el intervalo que representa la } \\
\text { densidad poblacional más baja será } \\
\text { considerado como Vulnerabilidad } 1 \text {. }\end{array}$ \\
\hline $\begin{array}{l}\text { Densidad de } \\
\text { Vivienda }\end{array}$ & $\begin{array}{l}\text { Se calcula considerando la cantidad } \\
\text { de viviendas en el radio dividido el } \\
\text { área del mismo. }\end{array}$ & 2 & $\begin{array}{l}\text { Se calculan cuatro intervalos iguales } \\
\text { entre el valor máximo y mínimo del } \\
\text { sector. Así, el corte que presenta la } \\
\text { mayor cantidad de población con } \\
\text { respecto a suárea será Vulnerabilidad } \\
4 \text { y el intervalo que representa la } \\
\text { densidad poblacional más baja será } \\
\text { considerado como Vulnerabilidad } 1 \text {. }\end{array}$ \\
\hline
\end{tabular}




\begin{tabular}{|c|c|c|c|}
\hline $\begin{array}{l}\text { Calidad } \\
\text { Constructiva } \\
\text { de la vivienda }\end{array}$ & $\begin{array}{l}\text { Se toman las categorías propuestas } \\
\text { por el Censo para generar los valores } \\
\text { de vulnerabilidad: satisfactoria - } \\
\text { básica - insuficiente. }\end{array}$ & 6 & $\begin{array}{l}\text { Vulnerabilidad 4: Calidad constructiva } \\
\text { de la vivienda insatisfactoria. } \\
\text { Vulnerabilidad 3: Calidad constructiva } \\
\text { de la vivienda básica. } \\
\text { Vulnerabilidad 1: Calidad constructiva } \\
\text { de la vivienda satisfactoria. }\end{array}$ \\
\hline Pobreza & $\begin{array}{l}\text { Se tiene en cuenta el nivel educativo } \\
\text { del Jefe de Hogar de cada radio, } \\
\text { y se lo combina con la variable } \\
\text { "Relación de Dependencia", es } \\
\text { decir, la cantidad de niños entre } \\
0 \text {-14 que dependen de la población } \\
\text { 15-64 en el radio. }\end{array}$ & 10 & 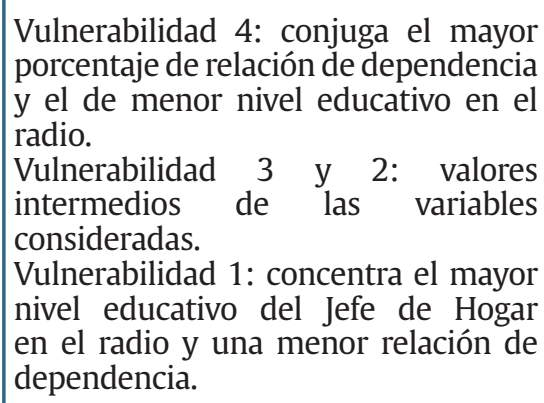 \\
\hline Áreas verdes & $\begin{array}{l}\text { Se considera la presencia o ausencia } \\
\text { de los mismos dentro de los radios. } \\
\text { Funcionan como superficies } \\
\text { filtrantes para el momento de la } \\
\text { precipitación, por lo que se toma } \\
\text { como positiva su presencia. }\end{array}$ & 3 & $\begin{array}{l}\text { Vulnerabilidad 3: ausencia de áreas } \\
\text { verdes en el radio. } \\
\text { Vulnerabilidad 2: presencia de áreas } \\
\text { verdes en el radio. }\end{array}$ \\
\hline
\end{tabular}

Fuente: elaboración propia

Al igual que con la Vulnerabilidad, también se utiliza la técnica de la ponderación para el cálculo de la Amenaza. Las variables escogidas para la realización de este mapa son las siguientes:

- Altimetría.

- Curso de agua.

- Cobertura vegetal.

- Red pluvial.

- Tipo de calle.

A continuación, se desarrollará brevemente cuál ha sido el método para cada una de ellas:

Altimetría: permite representar el relieve del terreno y por ello es considerada una de las variables más importantes dentro del Mapa de Amenaza. Se analizan las características y formas de las subcuencas, en el que el punto de descarga de cada una de ellas se define como un "punto crítico". Estos pueden constituir: el ingreso de agua de lluvia por escurrimiento superficial a la red pluvial a través de sus sumideros, o simplemente un sector donde se acumula agua de lluvia por falta de infraestructura hidráulica y por condiciones naturales del relieve. Asimismo, además del área de aporte superficial actual, estos puntos tienen en cuenta los escurrimientos en centros de esquinas y la red pluvial existente. Con la cantidad de superficie de aporte, contabilizadas a partir de manzanas afectadas, se determina el nivel de amenaza de cada punto crítico, siendo Amenaza 4, el que concentra un mayor volumen de agua, y por tanto la más alta y peligrosa. Esto se debe a que el volumen de agua precipitada es proporcional al porcentaje de permeabilidad, la intensidad de la lluvia y la superficie de aporte. De estas tres condiciones, la primera de ellas se pondera en otra variable (cobertura vegetal) y la segunda se considera eventos de tormentas recurrentes (45 mm en media hora). A partir del valor de su amenaza, a cada punto crítico se le determina una superficie que representa lo que ocuparía el agua en las calles si se acumula la escorrentía superficial y no escurre. A todos los puntos críticos, indistintamente de la amenaza que posean, se les asigna un área de influencia de cinco metros, que representa el centro de esquina en la intersección de las calles. A aquellos puntos que presentan una Amenaza 4, se les agregan dos áreas circulares de influencia continuas (a 20 y 80 metros del punto crítico), que disminuyen su amenaza a medida que se alejan del punto (valor de amenaza 3 y 2 respectivamente). En Amenaza 3, el área circular de influencia es una sola (a 20 metros y con una amenaza 2). En Amenaza 2, no tiene área de influencia, ya que el efecto es concentrado. Las áreas circulares de influencia son cortadas en base a las calles, ya que, por la experiencia, el agua se suele acumular sobre los ejes de circulación.

Los puntos críticos se definen con la colaboración de la Gerencia de Planeamiento y Obras de Obras 
Sanitarias, ya que cuenta con relevamientos topográficos, análisis de eventos meteorológicos ocurridos y experiencia en diseño de proyectos pluviales.

Curso de Agua: en el partido de General Pueyrredon existen varios arroyos. La gran mayoría están sobre el sector rural y con circulación sobre sus cauces naturales; los restantes han sido entubados o modificados sus escurrimiento, debido al crecimiento poblacional por la expansión de la ciudad. Tomando el eje del cauce del arroyo (obtenido a partir de la base de datos de OSSE), se distingue la amenaza máxima en esta línea, y el valor disminuye a medida que se aleja del mismo. Esto sigue la lógica de que, a la vez que se aleja del cauce, el peligro y las posibilidades de que el agua genere una inundación, va disminuyendo. Se proyectan estas situaciones siempre para un escenario de lluvias recurrentes o de diseño para períodos de 2 años.

Cobertura Vegetal: para el análisis de la Cobertura Vegetal se tiene en cuenta la permeabilidad aparente de la zona de estudio. Se trabaja con Imágenes Satelitales provenientes del satélite Sentinel 2A (Copernicus - ESA), y se seleccionan las bandas 4 y 8 referidas a la reflectividad del rojo $(0.665 \mathrm{~nm})$ e infrarrojo cercano( $0.842 \mathrm{~nm})$ respectivamente. Con estas imágenes se realiza un índice normalizado de vegetación (NDVI). Este da como resultado valores entre -1 y 1, los cuales significan la presencia 0 ausencia de vegetación. Mientras los valores estén más cercanos al -1, muestran una zona con muy baja vegetación, y presencia de cuerpos de agua (Amenaza 4), los valores entre - 0.1 y 0.1 explicitan zonas de suelos desnudos, arenas, material de construcción o calles (Amenaza 3). Valores entre 0.1 y 0.4 ejemplifican zonas de vegetación poco vigorosa (Amenaza 2), como pastizales y hierbas. Finalmente valores entre 0.4 y 1 responden a vegetación vigorosa, como campos cultivados o árboles (Amenaza 1). (European Space Agency, 2000-2020)

Red Pluvial: en esta variable se analiza la capacidad hidráulica de la red pluvial existente. En ella se relaciona la superficie de aporte aguas arriba del conducto, con la pendiente y la sección hidráulica del mismo ubicado aguas abajo. Estas dos últimas definen la capacidad de transporte de la red pluvial. Al igual que con los puntos críticos de la variable altimetría, la amenaza se define con la colaboración de la Gerencia de Planeamientos y Obras (OSSE), ya que cuenta con experiencia en análisis y diseño de conductos pluviales.

Tipo de Calle: para esta variable se realizó un relevamiento por parte del Área GIS de todas las calles de las distintas zonas de estudio. A partir de Google Earth, Google Maps, Google Street View y relevamiento en terreno, se identifican cuatro tipos de ejes. Estos se corresponden con los valores de amenaza.

En la Tabla 2 se enuncian las variables que se tuvieron en cuenta, los grados de los indicadores de cada una y la ponderación que se le otorga.

Tabla 2. Variables de Amenaza.

\begin{tabular}{|c|c|c|c|}
\hline Variable & Descripción & Ponderación & Grado de Amenaza \\
\hline Altimetría & $\begin{array}{l}\text { Representación del relieve del } \\
\text { terreno. A partir de un análisis } \\
\text { de las características y formas } \\
\text { de las subcuencas urbanas, se } \\
\text { determinan puntos críticos y } \\
\text { áreas afectadas por el mismo. }\end{array}$ & 13 & $\begin{array}{l}\text { Amenaza 4: superficie de aporte mayor a } \\
12 \text { manzanas. } \\
\text { Amenaza 3: superficie de aporte entre } 6 \text { y } \\
12 \text { manzanas. } \\
\text { Amenaza 2: superficie de aporte entre } 1 \text { y } \\
6 \text { manzanas. } \\
\text { Amenaza 1: el resto del área de estudio. }\end{array}$ \\
\hline Curso de Agua & $\begin{array}{l}\text { Tomando el eje del cauce del } \\
\text { arroyo, se distingue la amenaza } \\
\text { máxima en esta línea, se reduce } \\
\text { su valor a medida que se aleja } \\
\text { del mismo. }\end{array}$ & 4 & $\begin{array}{l}\text { Amenaza 4: a menos de } 25 \mathrm{mts} \text {. del cauce } \\
\text { principal. } \\
\text { Amenaza 3: entre } 25 \text { y } 75 \mathrm{mts} \text {. del cauce } \\
\text { principal. } \\
\text { Amenaza 2: entre } 75 \text { y } 125 \mathrm{mts} \text {. del cauce } \\
\text { principal. } \\
\text { Amenaza 1: a más de } 125 \mathrm{mts} \text {. del cauce } \\
\text { principal. }\end{array}$ \\
\hline
\end{tabular}




\begin{tabular}{|c|c|c|c|}
\hline $\begin{array}{l}\text { Cobertura } \\
\text { Vegetal }\end{array}$ & $\begin{array}{lrr}\text { Se tiene en cuenta la } \\
\text { permeabilidad aparente } & \text { de } \\
\text { la zona de estudio. Se trabaja } \\
\text { con material proveniente } \\
\text { del satéliterrentinel } & \text { 2A } \\
\text { (Copernicus-ESA) y se calcula a } \\
\text { partir de un NDVI. }\end{array}$ & 8 & $\begin{array}{l}\text { Amenaza } 4 \text { : valores del índice que rondan } \\
\text { entre }-1 \text { y } 0.1 \text {. Cobertura vegetal entre un } \\
0-15 \% \text {. } \\
\text { Amenaza } 3 \text { : valores del índice que varían } \\
\text { entre } 0.1 \text { y } 0.2 \text {. Cobertura vegetal entre un } \\
15-30 \% \text {. } \\
\text { Amenaza } 2 \text { : valores del índice que varían } \\
\text { entre } 0.2 \text { y } 0.4 \text {. Cobertura vegetal entre un } \\
30-60 \% \text {. } \\
\text { Amenaza } 1 \text { : valores del índice que varían } \\
\text { entre } 0.4 \text { y } 1 \text {. Cobertura vegetal mayor al } \\
60 \% \text {. }\end{array}$ \\
\hline Red Pluvial & $\begin{array}{l}\text { Se analiza la capacidad } \\
\text { hidráulica de la red pluvial } \\
\text { existente. Se relaciona la } \\
\text { superficie de aporte aguas } \\
\text { arriba del conducto y la } \\
\text { capacidad de transporte de la } \\
\text { red pluvial. }\end{array}$ & 9 & $\begin{array}{l}\text { Amenaza 4: elevada área de aporte y poca } \\
\text { capacidad hidráulica del conducto pluvial. } \\
\text { Amenaza 3: áreas de aporte moderadas } \\
\text { y capacidad hidráulica del conducto } \\
\text { reducida. } \\
\text { Amenaza 2: capacidad hidráulica del } \\
\text { conducto óptimo sin considerar el área de } \\
\text { aporte. } \\
\text { Amenaza 1: el resto del área de estudio. }\end{array}$ \\
\hline Tipo de calle & $\begin{array}{l}\text { Se calcula a partir del tipo de } \\
\text { material que conforma la calle } \\
\text { y la presencia o ausencia de } \\
\text { cordón - cuneta. }\end{array}$ & 6 & $\begin{array}{l}\text { Amenaza 4: calles de pavimento con } \\
\text { cordón cuneta. } \\
\text { Amenaza 3: calles de granza o tierra con } \\
\text { cordón cuneta; o pavimento sin cordón } \\
\text { cuneta. } \\
\text { Amenaza 2: calles de granza o tierra sin } \\
\text { cordón cuneta. } \\
\text { Amenaza 1: el resto del área de estudio. }\end{array}$ \\
\hline
\end{tabular}

Fuente: elaboración propia.

Los datos extraídos para la elaboración de las distintas variables son tomados de bases de datos oficiales, particularmente de OSSE y el Censo Nacional de 2010. Al recopilar la mayor cantidad de información desde la primera, se utiliza la proyección POSGAR 94 Argentina 6 la cual es la aplicada para todos los proyectos de la empresa. Para el caso de los datos censales, queda pendiente su actualización cuando se publiquen los resultados del Censo planificado para el corriente año (2020). Una vez obtenidas todas las variables del mapa, se procede a su rasterización. La mayoría de las variables se trabajan en formato vectorial (datos representados en líneas, puntos y polígonos), particularmente el Mapa de Vulnerabilidad. La rasterización se realiza con una resolución de $5 \mathrm{~m}^{2}$ por pixel para no perder información en la conversión de datos. El formato ráster (datos representados en píxeles) permite realizar cálculos con las bandas: multiplicar las categorías por la ponderación, y luego hacer las sumatorias. Este procedimiento hay que realizarlo primero entre las variables de cada Mapa, y después la suma de los dos mapas finales. Así es como se obtiene el Mapa de Riesgo del sector (Figura 3). 
Figura 3. Esquematización de la realización del Mapa de Riesgo.

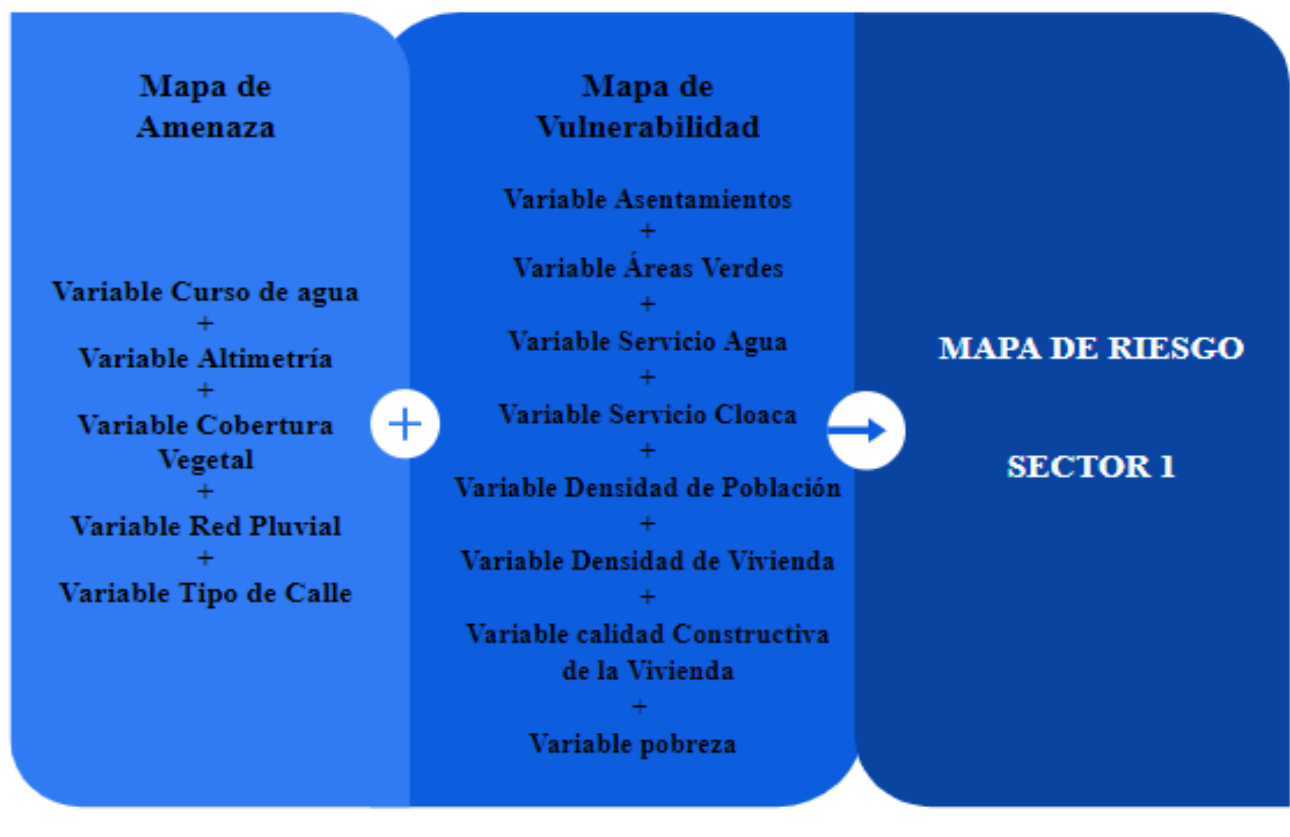

Fuente: elaboración propia.

A medida que se van realizando los distintos sectores, se va generando un mosaico con los distintos Mapas de Riesgo. Al finalizar el proceso, se deberá tener toda el área urbana del partido procesada.

El Mapa de Riesgo por anegamientos generado por el Equipo de Trabajo se aplica para lluvias recurrentes, entendiendo esto como eventos con precipitaciones frecuentes, de baja a media intensidad y que se dan con un período de tiempo de 2 años.

La visualización del Mapa de Riesgo se plantea de la siguiente manera. Dado que la sumatoria de los valores particulares de cada variable da como resultado intervalos diferentes, se procede a representar los resultados del Riesgo como valores mínimos y máximos. Estos se definen tomando aquellos que se encuentran entre el 1\% y el 99,5\% del total del sector. Debido a que esta selección de valores varía según la realidad de cada área, cuando se genere un mosaico, debe realizarse uniendo los Mapas de Riesgo, generando un nuevo ráster. La representación se realizará con datos cortados del conteo acumulativo del $1 \%$ al $99.5 \%$.

\section{Resultados}

Se analizó una superficie de 25,69 $\mathrm{km}^{2}$., lo cual representa un 25,76\% del total de la superficie del ejido urbano de la Ciudad de Mar del Plata $\left(99,73 \mathrm{~km}^{2}\right)$. Cabe aclarar también que de la totalidad de la red pluvial administrada por OSSE (340,07 km) se analizó y categorizó 70,41 km., representando un 20,79\% del total. Se han localizado para el área de estudio 504 puntos críticos altimétricos, de los cuales resultaron 38 dentro de la amenaza de valor máximo (4) y 108 puntos dentro del valor de amenaza alta (3). El estudio a partir de las imágenes satelitales provenientes del Sentinel $2 \mathrm{~A}$ dio como resultado que para el área de estudio, la cobertura vegetal menos amenazante cubre un 37,14\% de la superficie del sector, mientras que el valor más amenazante, un 11,03\%. Los valores intermedios de amenaza en la variable cobertura vegetal cubren un 36,28\% para el valor 2 y un 15,53\% para el valor de amenaza 3 . Es decir que en términos generales casi tres cuartos de la superficie del sector se encuentra bajo una cobertura vegetal que no representa una amenaza.

A corto plazo, con la extensión del análisis a los 13 sectores del ejido urbano marplatense, se podrá comprender qué variables son las problemáticas en los sectores de riesgo y actuar en consecuencia. Esto se circunscribe en lo mencionado anteriormente, relacionado con la necesidad de determinar políticas y estrategias para la implementación del proceso de Gestión Integral del Riesgo, mejorar el conocimiento de los barrios vulnerables, y generar nueva información para la mitigación del cambio climático.

En la Figura 4 se observan los tres mapas finales elaborados para esta primera parte del proyecto (Mapa de Amenaza, Mapa de Vulnerabilidad y Mapa de Riesgo). A continuación se enuncian algunos ejemplos de análisis que el Mapa de Riesgo permite hacer en el área de estudio. Esto es una prueba de la ventaja que estos productos cartográficos presentan. Los sectores a analizar son las áreas enunciadas como A, B, C y D. 
Figura 4. Mapa de Amenaza, Mapa de Vulnerabilidad y Mapa de Riesgo de la primera etapa del proyecto.

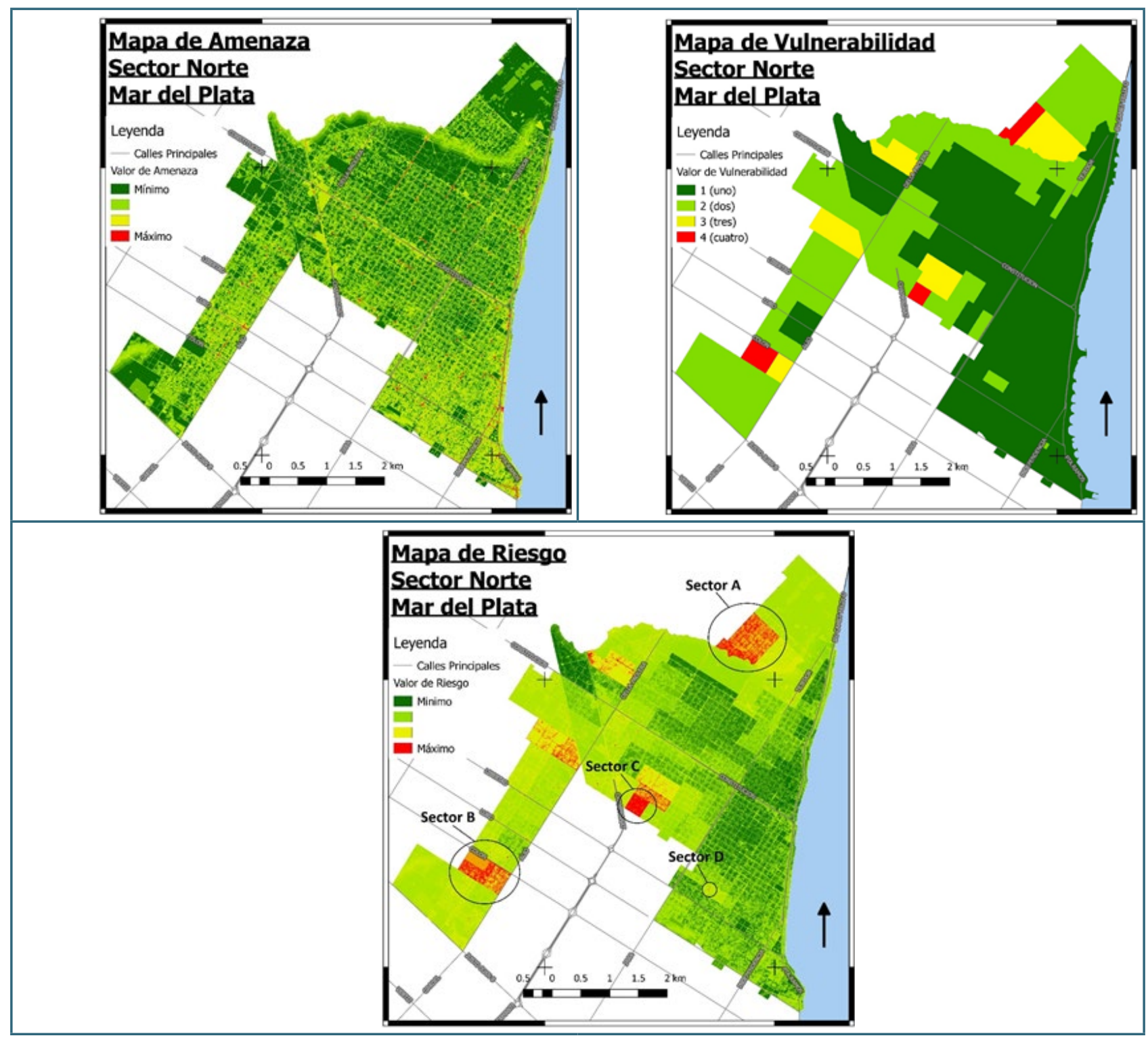

Fuente: elaboración propia.

Sector A(Marcos Sastre): a partir del análisis de imágenes de Google Earth(2020)y datos provenientes del Municipio de General Pueyrredón, se pudo apreciar cómo ha ido variando la población desde 2003 a 2020. Se observa un crecimiento acelerado durante el período mencionado, sobre todo de construcciones. Esto, sumado a una falta de planificación de la urbanización, hizo que aumentara la vulnerabilidad del barrio ante el fenómeno de inundaciones recurrentes. De acuerdo a los datos tomados del Censo de 2010, la calidad constructiva de las viviendas del sector se incluyó dentro de la Vulnerabilidad 4. Esto da la pauta de que la población del sector no cuenta con los recursos suficientes, y esto los vuelve aún más vulnerables a los eventos de inundación. Se corroboró con el alto valor obtenido en la variable pobreza. Siguiendo con la temática, en el área bajo estudio también se registró la presencia de asentamientos precarios, lo cual sumó a la hora de calcular la vulnerabilidad de esta población a eventos de inundación.

Se evidencian numerosos puntos críticos dentro de la variable de amenaza Altimetría. Esta cantidad de puntos conflictivos en los centro de esquina eleva el riesgo del sector ante una posible lluvia. Esto último también genera conflictos sociales, como la imposibilidad de transportarse o poder salir del barrio ante la inundación de los ejes de calle. Por último, la cercanía al arroyo La Tapera produce un riesgo inminente ante cualquier tipo de crecida o ocurrencia de eventos meteorológicos con lluvias intensas, aunque en este sector el arroyo para lluvias recurrentes no desborda. No obstante, el área lindante al arroyo se encuentra muy poco protegido y genera un aumento en el riesgo del sector.

La Figura 5 ejemplifica la vulnerabilidad de este espacio. Evidencia una inundación en el área durante un evento de precipitación en el año 2017. 
Figura 5. Anegamiento generado en el sector de Marcos Sastre, calle Costa Azul 3350, año 2017.

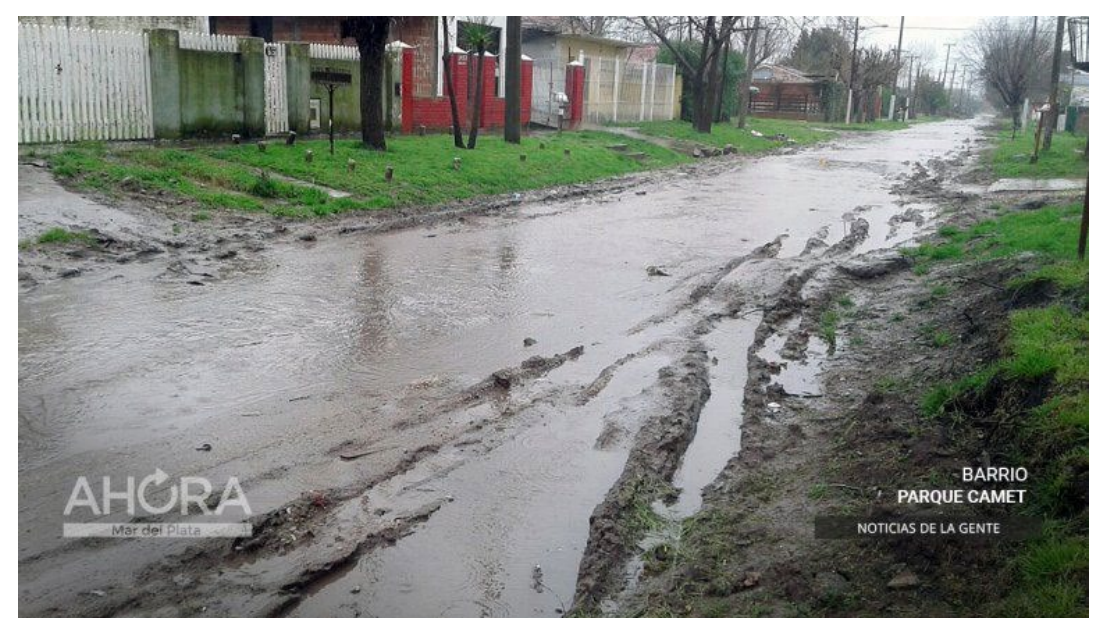

Fuente: https://ahoramardelplata.com.ar/

Sector B (Alió): a diferencia del caso del sector anterior, la problemática de este se define principalmente por variables del Mapa de Vulnerabilidad, es decir, de la cuestión socioeconómica. De acuerdo a los datos tomados del Censo de 2010, la calidad constructiva de las viviendas del sector se incluyó dentro de la Vulnerabilidad 4. Esto da la pauta de que la población del área no cuenta con los recursos suficientes, y esto los vuelve aún más vulnerables a los eventos de inundación. Se corroboró con el alto valor obtenido en la variable pobreza. Siguiendo con la temática, en el área bajo estudio también se registró la presencia de asentamientos precarios, lo cual sumó a la hora de calcular la vulnerabilidad de esta población a eventos de inundación.

Con respecto a las variables correspondientes al Mapa de Amenaza, se dan algunos sectores críticos en la intersección de la Av. Colón y la calle Termas de Río Hondo. Esto es así producto de la combinación de una alta amenaza en el tipo de calle (predomina el pavimento con cordón cuneta) y a un mal valor en cobertura vegetal, asociada a un elevado porcentaje de construcción por sobre espacios verdes.

En la Figura 6 se observa un ejemplo de esta situación, producto de un proceso de precipitación ocurrido en el año 2018.

Figura 6. Anegamiento generado en el sector de Alió, año 2018

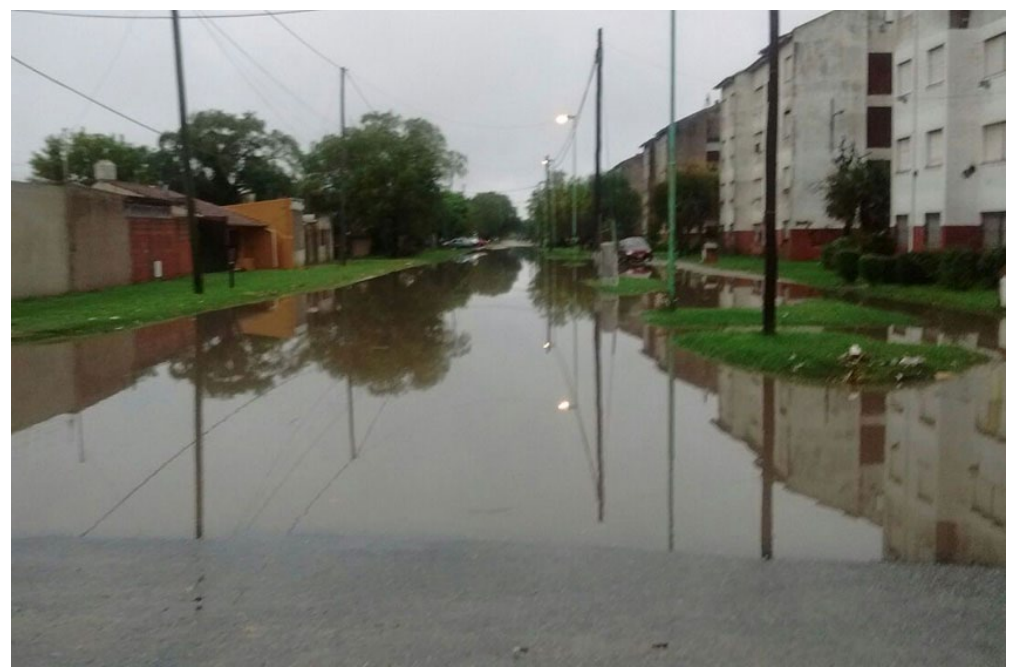

Fuente: https://elmarplatense.com

Sector C (Los Pinares): a partir del procesamiento de las variables, se determinaron conflictos en el área producto de la presencia de asentamientos y altos valores en Densidad de Población, Densidad de Vivienda y Pobreza. En cuanto a la amenaza, se evidencia un punto crítico altimétrico con valores elevados, al mismo tiempo que en este sector, el trazado vial corresponde a la categoría de pavimento con cordón cuneta. En este caso en particular, se presenta una situación similar a la del Sector B, en la cual los valores de vulnerabilidad son muy elevados y algunos valores de amenaza acompañan al valor de riesgo final (Figura 7). 
Figura 7. Anegamiento generado en la intersección de calles Bronzini e Ituzaingó, año 2017

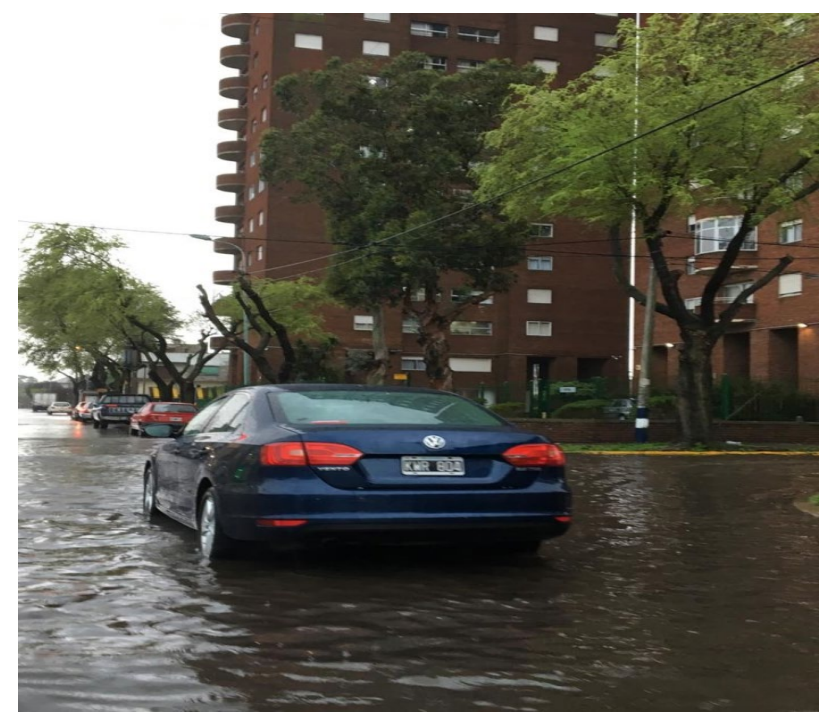

Fuente: https://www.lacapitalmdp.com/

Sector D (Constitución): todo lo contrario a los anteriores dos casos sucede en el sector D. Las variables de Amenaza para esta intersección fueron determinantes para que el valor final de Riesgo esté dentro de los más altos de toda el área estudiada. Como primer punto, se encuentra una red pluvial con amenazas importantes sobre este sector. Además, todas las calles son del tipo asfaltada con cordón cuneta, es decir, la que más amenaza genera; a lo cual hay que sumar una cobertura vegetal deficiente. Por último, en este pequeño sector también se encuentran varios puntos críticos altimétricos, uno de considerable importancia. La vulnerabilidad del sector, aporta al riesgo, presentando valores elevados en la variable de Calidad Constructiva, y no contando con ningún área verde en sus cercanías. En la Figura 8 se puede observar el valor de amenaza de la intersección junto con las tres principales variables amenazantes del área.

Figura 8. Mapa de Amenaza del sector; amenaza de Red Pluvial; amenaza de Altimetría; y amenaza de tipo de Calle para el sector de Constitución, intersección de las calles Ituzaingó y Misiones
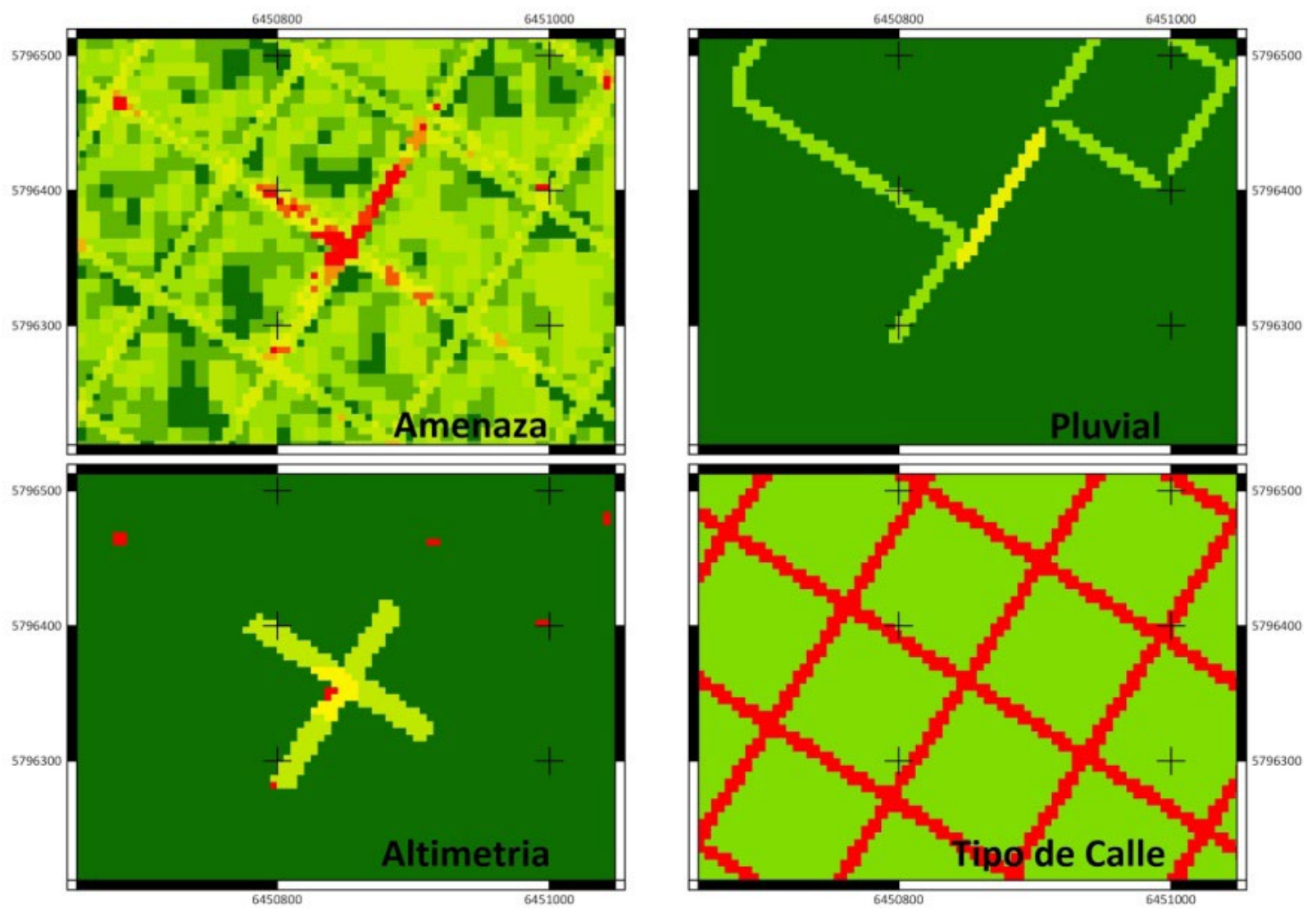

Fuente: elaboración propia. 


\section{Conclusiones}

Para llevar adelante el diagnóstico y cumplir los objetivos planteados para este trabajo, se consideraron todos los factores que pudieran verse influidos para un evento de precipitación recurrente. Por una parte, se consideraron aquellos vinculados con los temas físico-naturales (hidrológicos/hidráulicos) que se asocian directamente con la caracterización del terreno y del evento de inundación, a los cuales se suman los factores antrópicos, involucrando aspectos como orientación de los centros de esquina, tipo de calles, red pluvial existente, y tipo de cobertura vegetal. Finalmente, aunque no menos importantes, se incorporaron variables de vulnerabilidad a la que se expone la población.

Asimismo, el presente trabajo se incluye dentro de un marco referencial nacional y local y se alinea con el nuevo marco internacional que pone énfasis en la necesidad de reducir la vulnerabilidad e incrementar la resiliencia de las poblaciones frente a los eventos de inundaciones. Se refuerza la necesidad de integrar un enfoque transversal de prevención y gestión de riesgos.

A continuación se ordenan las conclusiones alcanzadas en el trabajo expuesto:

- El valor de precipitación para un evento recurrente equivale estadísticamente a $32 \mathrm{~mm}$ en 1 hora de duración de tormenta. El último evento meteorológico de importancia ocurrido en la ciudad registró $55 \mathrm{~mm} / \mathrm{h}$, lo cual corroboró muchos de los resultados alcanzados en el trabajo.

- Se detectan dentro de los sectores de riesgo instalaciones de OSSE que podrían verse afectadas. Esta información permitirá tomar medidas preventivas ante un posible ingreso de agua de lluvia no deseada.

- Se detectan dentro de los sectores de riesgo edificios vulnerables (infraestructura educativa, sanitaria y geriátrica) que podrían verse afectados.

- Defensa Civil podrá gestionar nuevos puntos de evacuación a partir de la toma de conocimiento del Mapa de Riesgo.

- El Mapa de Riesgo valida los proyectos ya ejecutados por OSSE y los que están por ejecutar.

- Sumará una herramienta más al área Pluviales de OSSE, ya que podrá complementar los trabajos de mantenimiento preventivo que realiza, teniendo en cuenta el Mapa de Riesgo.

- El trabajo se alinea y puede contribuir a definir indicadores para varias de las metas de los ODS.

- Este tipo de estudios genera un antecedente que brindará la posibilidad de replicar la metodología propuesta en otros municipios de la región.

- También se caracterizan diversas formas en la cual el Mapa de Riesgo de Inundaciones de la ciudad respalda en forma de herramienta a los siguientes proyectos:

- La gestión de obras pluviales ante organismos Provinciales / Nacionales / Internacionales.

- El Estudio SUDS - Sistemas Urbanos de Drenajes Sostenibles, en desarrollo por la Gerencia de Planificación y Obras de OSSE.

- Sumar su aporte en los Planes Locales de Acción Climática (contexto de la RAMCC).

- La gestión de solicitud de presupuesto en el contexto de la Ley Nacional de Presupuestos Mínimos de Adaptación y Mitigación al Cambio Climático Global.

El Mapa de Riesgo a Inundaciones hasta aquí presentado no sólo demuestra su factibilidad ante distintos eventos de precipitación, sino que además es una herramienta muy útil a la hora de desarrollar estrategias de mitigación y adaptación. Esto es de suma importancia, sobre todo frente a la forma en que se desarrollarán los sucesos de lluvias a mediano plazo.

OSSE es la empresa sanitaria municipal del Partido de General Pueyrredon y, como tal, presta los servicios de agua, cloaca y pluviales. Su misión consiste en garantizar los beneficios del saneamiento, a través de una gestión eficiente y sustentable de los recursos. Se trabaja para alcanzar la universalización (en relación a la cobertura) y con el objetivo primordial de contribuir a la calidad de vida de la comunidad. De ahí su aporte con la elaboración del Mapa de Riesgo a Inundaciones para la ciudad.

\section{Referencias bibliográficas}

Armentis Parras, G. E., Dorado Delgado, J., Onelia Rodríguez Roa, A., y Ruiz Murcia, J. K (2015). Escenarios de Cambio Climático para precipitación y temperatura en Colombia. Tercera Comunicación Nacional de 
Cambio Climático, Bogotá, Colombia: Instituto de Hidrología, Meteorología y Estudios Ambientales. PNUD

Banco Interamericano de Desarrollo. (2014). La economía del Cambio Climático en el Estado Plurinacional de Bolivia (1 ed.) CEPAL - BID

Ciaffardini, F., Scarano, S., Smarke, L., y Viand, J. (2018). La gestión de riesgos hidrometeorológicos en el municipio de San Antonio de Areco. Experiencias y reflexiones acerca de su implementación en la política municipal [Presentación de paper]. 4to Encuentro de Investigadores en Formación en Recursos Hídricos, San Antonio de Areco, Argentina. https://www.ina.gov.ar/ifrh-2018/pdf/ IFRH_2018_paper_56.pdf

Daga, D. (2014). Evaluación de la vulnerabilidad socio-ambiental del periurbano de Mar del Plata y lineamientos para el Ordenamiento Ambiental del Territorio. [Tesis de grado para optar por el título de Licenciatura en Diagnóstico y Gestión Ambiental, Facultad de Ciencias Humanas de la Universidad Nacional del Centro de la Provincia de Buenos Aires]. Repositorio RIDAA - UNICEN: https://www.ridaa.unicen.edu.ar/xmlui/bitstream/handle/123456789/2104/Tesis\%20Daga\%20 Daiana.pdf? sequence=1\&isAllowed=y

Etulain, J. C. y López, I. (2017). Inundaciones Urbanas. Mapas de riesgo y lineamientos de ordenamiento territorial en la región del Gran La Plata. Aspectos teórico-metodológicos y propósitos. Estudios del hábitat, 15 (2), 2 - 21. https://doi.org/10.24215/24226483e030

European Space Agency [ESA] (2000-2020). Level-2A Algorithm Overview. https://earth.esa.int/web/ sentinel/technical-guides/sentinel-2-msi/level-2a/algorithm

García-Soriano, D., Quesada-Román, A., y Zamorano-Orozco, J.J. (2020). Geomorphological hazards susceptibility in high-density urban areas: a case study of Mexico City. Journal of South American Earth Sciences, 102, 102667. https://doi.org/10.1016/j.jsames.2020.102667

Gobierno de la ciudad de Santa Fe (2014). Aprender de los desastres. La Gestión local del riesgo en Santa Fe, a 10 años de la inundación de 2003. UNISDR. https://mercociudades.org/wp-content/uploads/2020/10/ Aprender-de-los-Desastres.pdf

Grupo Intergubernamental de Expertos sobre el Cambio Climático (2019). Climate Change and Land. An IPCC Special Report on climate change, desertification, land degradation, sustainable land management, food security and greenhouse gas fluxes in terrestrial ecosystems. https://www.ipcc.ch/site/assets/ uploads/2019/11/SRCCL-Full-Report-Compiled-191128.pdf

Grupo Intergubernamental de Expertos sobre el Cambio Climático (2019). AR6 Synthesis Report: Climate Change 2022. https://www.ipcc.ch/report/sixth-assessment-report-cycle/

Grupo Intergubernamental de Expertos sobre el Cambio Climático (2018). Informe especial del IPCC sobre los impactos del calentamiento global de $1.5^{\circ} \mathrm{C}$ con respecto a los niveles preindustriales y las trayectorias correspondientes que deberían seguir las emisiones mundiales de gases de efecto invernadero, en el contexto del reforzamiento de la respuesta mundial a la amenaza del cambio climático, el desarrollo sostenible y los esfuerzos por erradicar la pobreza. Afirmaciones principales del Resumen para responsables de políticas. https://www.ipcc.ch/site/assets/uploads/sites/2/2019/09/SR15 Headline_Statements_Spanish.pdf

Hernández, J. y Vieyra, A. (2010). Riesgo por inundaciones en asentamientos precarios del periurbano. Morelia, una ciudad media mexicana. ¿El desastre nace o se hace?. Revista de Geografía Norte Grande, 47(2), 45 - 62. http://dx.doi.org/10.4067/S0718-34022010000300003

Instituto Nacional de Estadísticas y Censo (2020) Calidad de los materiales de la vivienda en el Censo Nacional de Población, Hogares y Viviendas 2001 y 2010. https://www.indec.gob.ar/ftp/cuadros/poblacion/ informe_calmat_2001_2010.pdf

Jha, Abhas K. Bloch, R. y Lamond, J. (2012). Ciudades e Inundaciones : guía para la gestión integrada del riesgo de inundaciones en ciudades en el Siglo 21. World Bank. https://openknowledge.worldbank. org/handle/10986/2241

Kohler, A., Jülich, S. y Bloemertz, L. (2004). Manual: El análisis del riesgo - una base para la gestión de riesgo de desastres naturales. Siebel Druck \& Grafik, Lindlar.

Ley 27.287 de 2016. (2016, 28 de septiembre). Boletín Oficial de la República Argentina.

Ley 27.520 de 2019. (2019, 20 de diciembre). Boletín Oficial de la República Argentina.

Marengo, J. A. (2002). Escenarios de Cambio Climático em América del Sur: impactos, vulnerabilidad y 
adaptación em relación a extremos. Centro de Ciencia do Sistema Terrestre - CCST. http://pnud. cptec.inpe.br/itens/entrenamiento2/apresentacoes/Escenarios\%20de\%20cambio\%20climatico\%20 en\%20America\%20del\%20Sur_Jose\%20Marengo.pdf

Meza, J. C.; Ramírez, M. L. y Contreras, F. I. (2017). Cartografía de áreas de riesgo a inundaciones y anegamientos a partir de modelos digitales de elevación de General José de San Martín (Chaco, República Argentina). Contribuciones Científicas GAEA (29) 149 - 164. https://repositorio.unne. edu.ar/bitstream/handle/123456789/27676/RIUNNE_FHUM_AR_Meza-Ram\%c3\%adrez-Contreras. pdf? sequence $=1 \&$ isAllowed $=y$

Ministerio de Medio Ambiente del Gobierno de Chile (2014). Plan nacional de Adaptación al Cambio Climático. https://mma.gob.cl/wp-content/uploads/2016/02/Plan-Nacional-Adaptacion-CambioClimatico-version-final.pdf

Olcina Cantos, J (2017). Incremento de episodios de inundación por lluvias de intensidad horaria en el sector litoral mediterráneo español: análisis de tendencias en Alicante. SÉMATA. Ciencias Socials e Humanidades, 2017(29) 143 - 163. https://rua.ua.es/dspace/bitstream/10045/73413/1/2017_ Olcina_Semata.pdf

Organización de las Naciones Unidas (2018). La Agenda 2030 y los Objetivos de Desarrollo Sostenible: una oportunidad para América Latina y el Caribe. https://repositorio.cepal.org/bitstream/ handle/11362/40155/24/S1801141_es.pdf

Quesada-Román, A., Villalobos-Portilla, E., y Campos-Durán, D. (2021). Hydrometeorological disasters in urban areas of Costa Rica, Central America. Environmental Hazards, 20(3), 264-278. https://doi.org/ 10.1080/17477891.2020.1791034

Red Argentina de Municipios Frente al Cambio Climático (2020). Plan Local de Acción Climática. https:// www.ramcc.net/servicio.php?id=4

Renda, E., Rozas Garay, M., Moscardini, O. y Torchia, N. P (2017). Manual para la elaboración de mapas de riesgo. Ministerio de Seguridad de la Nación. https://www.mininterior.gov.ar/planificacion/pdf/ Manual-elaboracion-mapas-riesgo.pdf

Sánchez Gonzáles, D. (2011). Peligrosidad y exposición a los ciclones tropicales en ciudades del Golfo de México. El caso de Tampico. Revista de Geografía Norte Grande, 50(2), 151 - 170. http://dx.doi. org/10.4067/S0718-34022011000300009

Schomwandt, D. R.; Lucioni, N.y Andrade, M. I.(2016). Cartografía de riesgo de inundación y la representación de la vulnerabilidad en gran La Plata, Buenos Aires. Revista de geología aplicada a la Ingeniería y al ambiente, 36 (1), 15 - 28. http://sedici.unlp.edu.ar/bitstream/handle/10915/89775/Documento_ completo.9600.pdf? sequence $=1$ \&isAllowed $=\mathrm{y}$

Secretaría de Ambiente y Desarrollo Sustentable (2015). Tercera Comunicación Nacional de la República Argentina a la Convención Marco de las Naciones Unidas sobre el Cambio Climático. https://www. argentina.gob.ar/ambiente/cambio-climatico/tercera-comunicacion

Tucci, C. E. M (2007). Gestión de Inundaciones Urbanas. Porto Alegre, Brasil: WMO OMM.

Uijt den Bogaard, J. S. y Cotelo, A. (2020). Plan Local de Acción frente al Cambio Climático. Bariloche 2020-2030. RMCC. https://pactodealcaldes-la.org/wp-content/uploads/2017/10/Plan-Local-de-Acci\%C3\%B3nClim\%C3\%A1tica-San-Carlos-de-Bariloche.pdf 